\title{
Nanofitin as a New Molecular-Imaging Agent for the Diagnosis of Epidermal Growth Factor Receptor Over-Expressing Tumors
}

\section{Marine Goux, ${ }^{\dagger}$ Guillaume Becker, ${ }^{\dagger}$ Harmony Gorre, ${ }^{\perp}$ Sylvestre Dammicco, ${ }^{\dagger}$ Ariane Desselle, ${ }^{\perp}$ Dominique affilogic Egrise, ${ }^{\S}, / /$ Natacha Leroi, ${ }^{\#}$ Francọis Lallemand, ${ }^{\dagger}$ Mohamed Ali Bahri, ${ }^{\dagger}$ GillesDoumont, ${ }^{\S}$ AlainPleńevaux, ${ }^{\dagger}$ Mathieu Cinier, ${ }^{\perp}$ and André Luxen ${ }^{\dagger}$

\section{INTRODUCTION \& METHODS}

Nanofitins are cysteine-free protein scaffolds derived from the hyperstable DNA-binding protein Sac7d (7 kDa, 66 amino acids) of Sulfolobus acidocaldarius [1]. High-affinity nanofitins have been easily engineered by ribosome-display over a wide range of targets by the full randomization of 10 to 14 amino acid residues localized in the DNA-binding site of Sac7d. In this study, the anti-EGFR Nanofitin Cys-B10 was site-specifically labeled with ${ }^{18} \mathrm{~F}$ by site-specific conjugation with the prosthetic group ${ }^{18} \mathrm{~F}-4$-fluorobenzamido- $\mathrm{N}$-ethylaminomaleimide ( $\left.{ }^{18} \mathrm{~F}-\mathrm{FBEM}\right)$, using a unique cysteine residue specifically introduced in C-terminus [2].
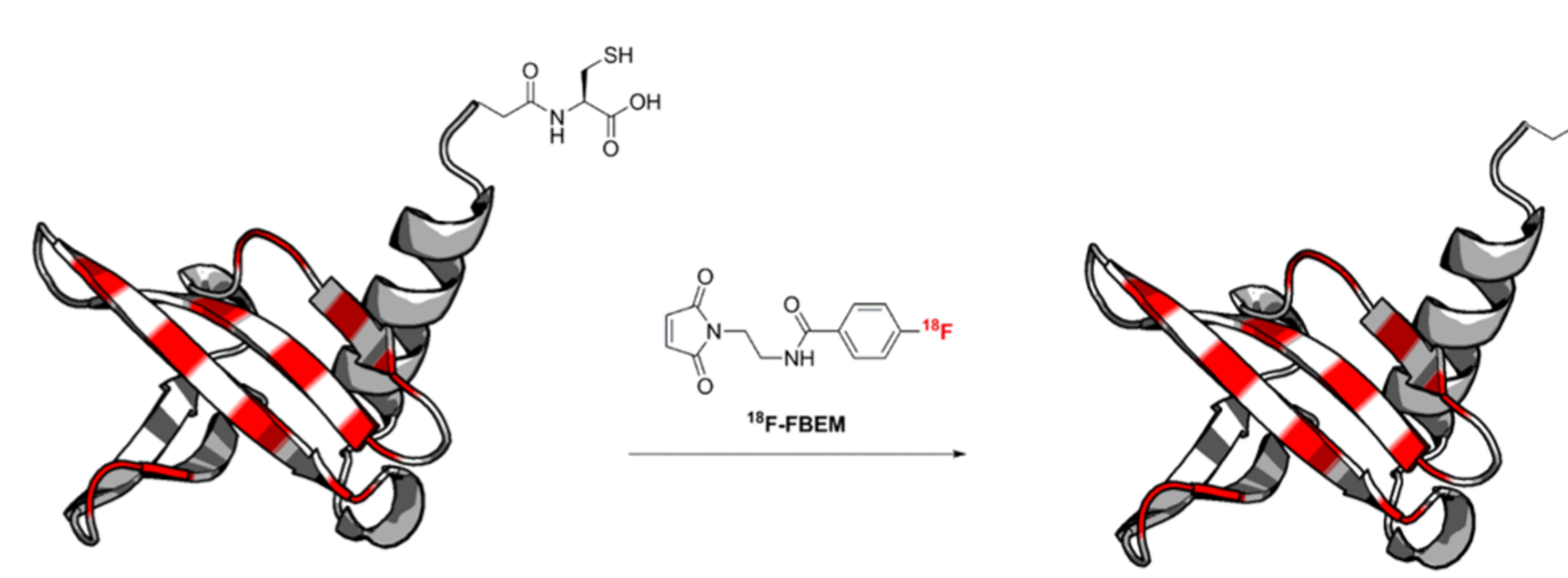

The resulting probe, ${ }^{18} \mathrm{~F}-\mathrm{FBEM}-\mathrm{Cys}-\mathrm{B} 10$, was then injected in a double-bearing tumor model to evaluate the biodistribution and the ability of the radiolabeled protein to specifically target in vivo the EGFR over-expressing A431 tumor.

\section{Radiolabeling}

The radioactive ${ }^{18} \mathrm{~F}-\mathrm{FBEM}$ (molar activity: $830 \mathrm{MBq} / \mathrm{nmol}$ ) was automatically synthetized on a FastLab Multitracer (GE Healthcare) as previously described [2]. The Nanofitin Cys-B10 was incubated with $\mathrm{Ni}-$ nitrilotriacetic acid magnetic beads (GE Healthcare) in the presence of TCEP-HCl (50 equiv, $30 \mathrm{~min}, 25^{\circ} \mathrm{C}, \mathrm{pH}$ adjusted at 8). Beads were washed with phosphate buffer ( $200 \mathrm{mM}, \mathrm{pH} 7.4)$ and incubated with ${ }^{18} \mathrm{~F}-\mathrm{FBEM}$ freshly resuspended in phosphate buffer. Beads were washed with phosphate buffer, and the radiolabeled Nanofitin called ${ }^{18} \mathrm{~F}-\mathrm{FBEM}-\mathrm{Cys}-\mathrm{B} 10$ (effective molar activity: $37.0-53.6 \mathrm{MBq} / \mathrm{nmol}$ ) was eluted with imidazole.

\section{microPET}

- Emission: 2 h dynamic scan, Siemens FOCUS 120.

- Transmission: 10 min., 57Co point source.

- ${ }^{18} \mathrm{~F}-\mathrm{FDG}: 10 \mathrm{~min}$. static acquisition, $50 \mathrm{~min}$. after i.p. injection.

\section{Anatomical reference}

- MRI anatomical whole body imaging, 9.4 T micro-MRI (Agilent Technologies).

- Micro-CT anatomical whole body imaging (Trifoil).

\section{HIGHLIGHTS}

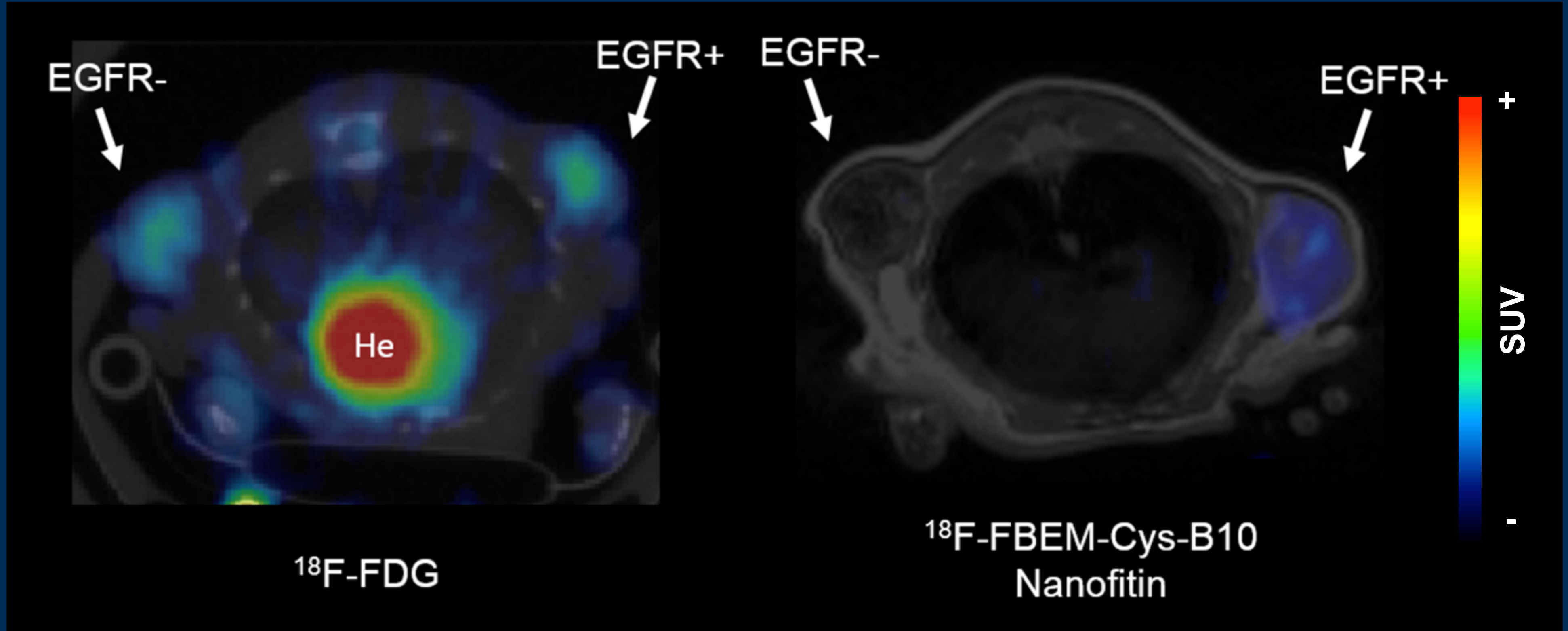

Targeting of the EGFR-positive tumor A431 by the radiolabeled anti-EGFR Nanofitin

A Co-registered transversal sections of PET and CT $1 \mathrm{~h}$ after the injection of ${ }^{18} \mathrm{~F}-\mathrm{FDG}(9 \mathrm{MBq})$ in a xenograft model under isoflurane anesthesia (blood glucose level of $73 \mathrm{mg} / \mathrm{dL}$ and weight of $29 \mathrm{~g}$ ). $\mathrm{He}$ : heart. B Co-registered transversal sections of PET and MRI $2 \mathrm{~h}$ after injection in xenograft model under isoflurane anesthesia of ${ }^{18} \mathrm{~F}-\mathrm{FBEM}-\mathrm{Cys}-\mathrm{B} 10(19 \mathrm{MBq} / 100 \mu \mathrm{L})$.

REFERENCES

[1] Mouratou, B. et al, PNAS 2007. [2] Dammicco, S. et al, Nucl Med Biol, 2017.

ACKNOWLEDGEMENTS \& SPONSORS

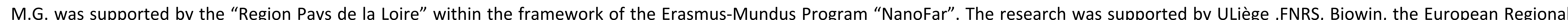
Development Fund and the Walloon Region.

\section{RESULTS \& DISCUSSION}

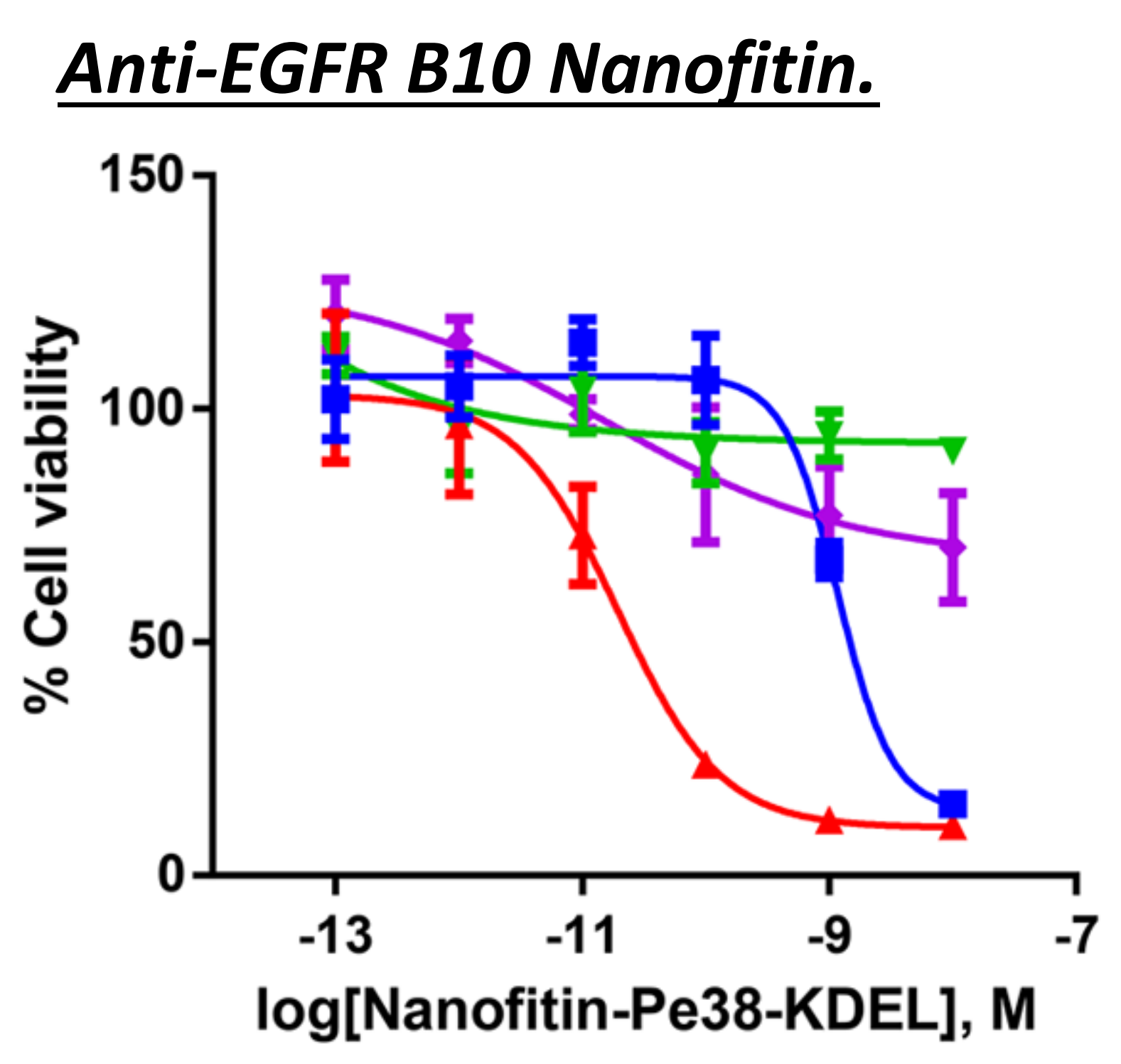
Nanofitins. $-\alpha$ EGFR_NF1-Pe38-KDEL

$\alpha$ EGFR NF2-Pe38-KDEL

IrrNF-Pe38-KDEL

Measurement of $A 431$ cells viability after incubation with Nanofitins fused to the Pe38 toxin.

aEGFR_B10_Pe38-KDEL, anti-EGFR B10 Nanofitin.

aEGFR_NF1- and NF2-Pe38-KDEL, other anti-EGFR

IrrNF-Pe38_KDEL, irrelevant Nanofitin.

The non-internalizing profile of $\alpha$ EGFR_B10_Pe38-KDEL appeared not to be shared with he two other anti-EGFR Nanofitins NF1.

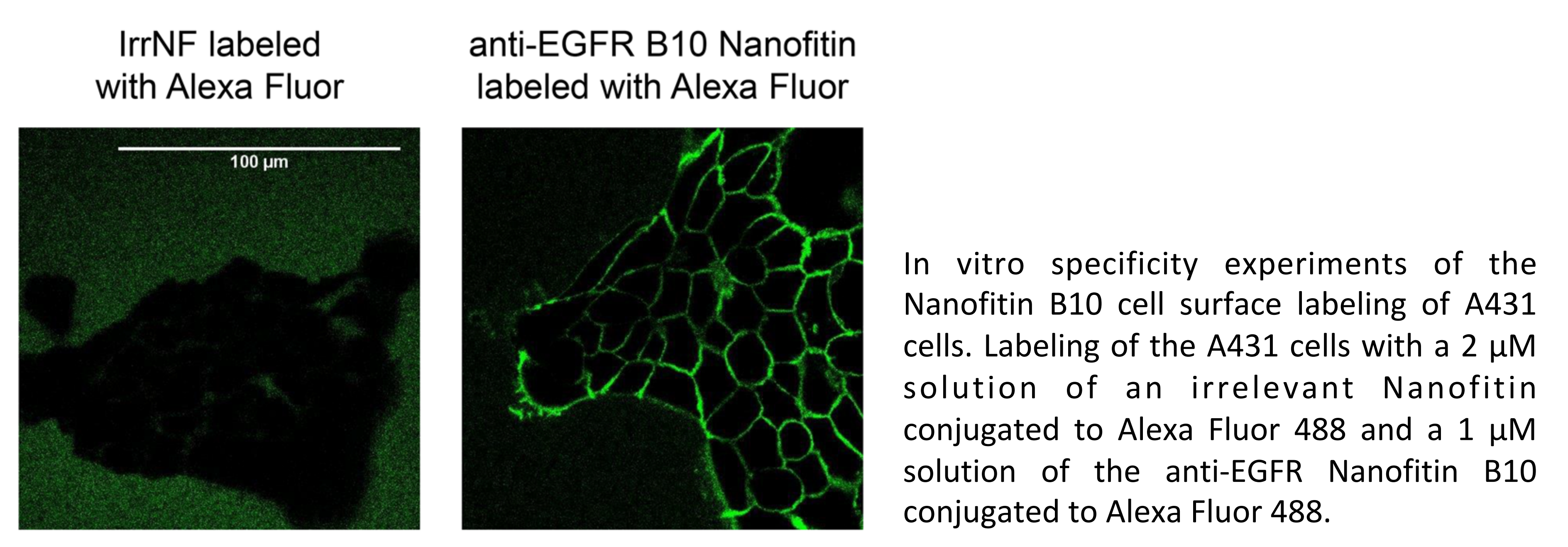

Time-lapse microscopy on A431 cells incubated with either Alexa Fluor 488 labeled anti-EGFR B10 or anti-egg white lysozyme H4 Nanofitin (negative control) revealed a fast accumulation (visible after few seconds) of fluorescence on cells membrane for B10, while no targeting was observed with the irrelevant Nanofitin.

\section{Specificity of Tumor Targeting}

Biodistribution of ${ }^{18} \mathrm{~F}-\mathrm{FBEM}-\mathrm{Cys}-\mathrm{B} 1$ at $2.5 \mathrm{~h}$ Post-Injection.

\begin{tabular}{lc}
\hline \multicolumn{1}{c}{ Tissues } & $\begin{array}{c}\text { Xenograft } \\
\text { model }\end{array}$ \\
\hline Blood & $0.32 \pm 0.07$ \\
\hline Brain & $0.02 \pm 0.01$ \\
\hline Bone & $0.20 \pm 0.01$ \\
\hline Liver & $1.13 \pm 0.52$ \\
\hline Kidney & $1.55 \pm 0.57$ \\
\hline Heart & $0.17 \pm 0.03$ \\
\hline Spleen & $0.27 \pm 0.08$ \\
\hline Skin & $0.28 \pm 0.12$ \\
\hline Muscle & $0.12 \pm 0.03$ \\
\hline Lung & $0.63 \pm 0.31$ \\
\hline Tumor A431 & $1.42 \pm 0.18$ \\
\hline Tumor H520 & $0.56 \pm 0.10$ \\
\hline
\end{tabular}

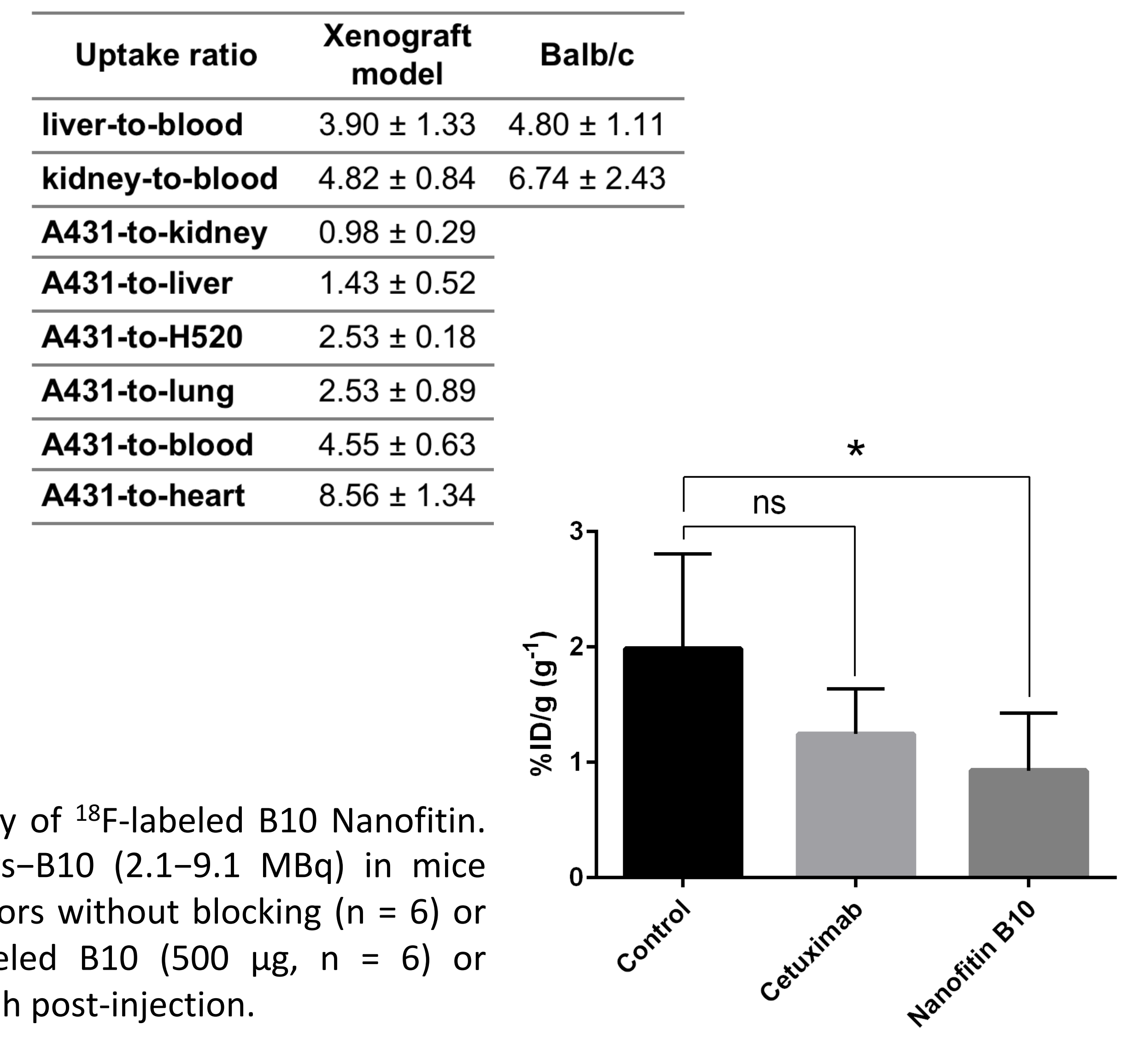

A431 tumor targeting and specificity of ${ }^{18} \mathrm{~F}$-labeled B10 Nanofitin. Uptake in tumors of ${ }^{18} \mathrm{~F}-\mathrm{FBEM}-\mathrm{Cys}-\mathrm{B} 10(2.1-9.1 \mathrm{MBq})$ in mice carrying EGFR-expressing A431 tumors without blocking $(n=6)$ or Cetuximat $(45$ amounts of nonlabeled B10 (500

\section{SUMMARY}

In this study, we provided the first report of the use of the Nanofitin scaffold for generating targeted PET radiotracers, using the anti-EGFR B10 Nanofitin as proof-of-concept. ${ }^{18} \mathrm{~F}-\mathrm{FBEM}-\mathrm{Cys}-\mathrm{B} 10$ shows a favorable in vivo profile. The possibility to drive Nanofitins molecular recognition capability, over a fast and tunable in vitro selection system, could facilitate the development of valuable PET-based companion diagnostics.

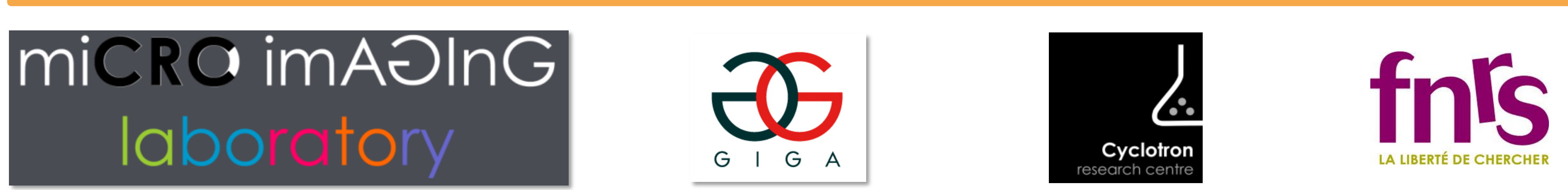

